\title{
ACTIVIDAD IN VITRO DE BACTERIAS ENDÓFITAS FIJADORAS DE NITRÓGENO Y SOLUBILIZADORAS DE FOSFATOS ${ }^{1}$
}

\author{
Alexander Pérez-Cordero², Adriana Tuberquia-Sierra², Daniel Amell-Jímenez ${ }^{2}$
}

\section{RESUMEN}

Actividad in vitro de bacterias endófitas fijadoras de nitrógeno y solubilizadoras de fosfatos. El objetivo de este estudio fue evaluar in vitro la actividad fijadora de nitrógeno y solubilizadora de fosfato de bacterias endófitas de pasto colosoana (Bothriochloa pertusa). Se colectó la raíz, los tallos y las hojas del pasto en cuatro zonas agroecológicas del municipio de Corozal, Sucre, Colombia, durante el segundo semestre del año 2012. Cada tejido fue sometido a proceso de desinfección superficial. Se aislaron bacterias endófitas en medio de cultivo agar $\mathrm{R}_{2} \mathrm{~A}$, a partir de cada tejido se determinó la densidad poblacional (UFC/g de tejido), por conteo en superficie; la separación de morfotipos se realizó mediante la forma, color, tamaño y apariencia. La actividad fijadora de nitrógeno y solubilizadora de fosfato se evaluó in vitro sobre medios de cultivos específicos. Todos los resultados obtenidos fueron analizados utilizando el programa estadístico R. Hubo diferencias significativas para densidades poblacional de bacterias con respecto a tejido, con mayores valores en raíz $\left(1,61 \times 10^{10} / \mathrm{g}\right.$ raíz), seguida de tallo $\left(7,44 \times 10^{9} / \mathrm{g}\right.$ tallo) y los valores más bajos se reportaron para hojas $\left(5,42 \times 10^{9} / \mathrm{g}\right.$ hoja $)$. Se encontró significancia entre la densidad poblacional con relación a los factores de zona, fincas y tipo de tejido analizado. Los resultados de la identificación con kit API20E confirmaron la presencia de las bacterias endófitas Aeromonas salmonicida y Pasteurella pneumotropica con capacidad simultánea de solubilizar fosfatos y fijar nitrógeno.

Palabras claves: Bothriochloa pertusa, microorganismos endófitos, biofertilizantes para pasto.

\begin{abstract}
In vitro activity of nitrogen fixating and phosphate solubilizing bacteria. The aim of this work was to evaluate the in vitro nitrogen-fixing activity and phosphate solubilizing activities of endophytic bacteria isolated from colosoana grass (Bothriochloa pertusa). The grass tissue was collected from root, stems and leaves from different agroecological zones in the municipality of Corozal, Sucre, Colombia. Each tissue underwent surface cleaning, maceration, and isolation of endophytic bacteria in $\mathrm{R}_{2} \mathrm{~A}$ agar medium. Population density was determined by plate counts as $\mathrm{CFU} / \mathrm{g}$ of tissue, morphotypes were then identified by shape, color, size, and appearance. Each morphotype was evaluated in vitro for nitrogen-fixation and phosphate solubilization in specific culture media. All results were analyzed using the statistical program $\mathrm{R}$. The test results showed a significant differences in terms of population density of endophytic bacteria per type of tissue. A significant differences were found between population density with respect to tissue; the highest values were observed in roots $\left(1.61 \times 10^{10} / \mathrm{g}\right.$ root $)$, followed by stems (7.44 x 109 $/ \mathrm{g}$ stem) while the lowest values corresponded to leaves $\left(5.42 \times 10^{9} / \mathrm{g}\right.$ leaf). Significance was also found between population density with respect to other factors analyzed including: zone, farm and type of tissue. Results with the API20E identification kit confirmed the presence of the endophytic bacterium Aeromonas salmonicida and Pasteurella pneumotropica, which are capable of solubilizing phosphates and fixate nitrogen simultaneously.
\end{abstract}

Keywords: Bothriochloa pertusa, endophytic microorganisms, grass biofertilizers.

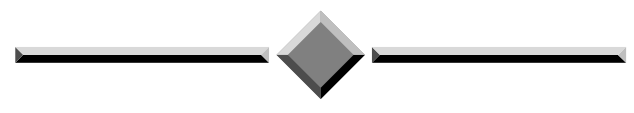

\footnotetext{
Recibido: 20 de febrero, 2014. Aceptado: 30 de junio, 2014. Parte del proyecto "Aislamiento y evaluación in vitro de la actividad fijadora de nitrógeno y solubilizadora de fosfato de bacteria asociadas al pasto colosoana (Botriochloa pertusa (L) A. Camus) en el departamento de Sucre" el cual fue financiado por la Universidad de Sucre, Colombia.

2 Laboratorio de Investigaciones Microbiológicas, Facultad de Ciencias Agropecuarias, Universidad de Sucre. Campus universitario Carrera 28 \# 5-267. Teléfono: (052) 82 1240. Sincelejo (Sucre), Colombia. alexander.perez@unisucre.edu.co (Autor para correspondencia), adrijostin@ hotmail.com, danielcat89@gmail.com
} 


\section{INTRODUCCIÓN}

En la región Caribe Colombiano, la ganadería es una actividad relevante, dada el área de suelos dedicados a pasturas, la cual representa el 18,2\% del área de pastos del país. La subregión Sabanas del departamento de Sucre posee 164000 ha con pasturas, en su mayoría con Bothriochloa pertusa (L) A. Camus, lo que corresponde al $21,3 \%$ del área total de pasto del departamento. Los factores fisiográficos, las acciones antropogénicas degenerativas del medio natural y el empleo de tecnologías inadecuadas, han traído como consecuencia, la degradación de propiedades físicas, químicas y biológicas del suelo, lo que limita la oferta y calidad de pastos y forrajes principalmente en temporada seca (Pérez et al., 2010).

Debido a la estacionalidad de las lluvias, se produce la escasez o falta total de forraje durante la época seca en el departamento de Sucre. Esta escasez de forraje es también producto de los diferentes grados de compactación que presentan los suelos, problemas erosivos, niveles bajos de fertilidad. Además, la práctica del pastoreo extensivo se genera una degradación de las praderas. La agricultura intensiva ha aumentado el rendimiento de las cosechas pero también ha generado graves problemas de contaminación ambiental, gasto energético, degradación y pérdida de suelo. La comprensión de los agroecosistemas es clave para determinar los sistemas eficaces en agricultura (Aguilera, 2005).

La creciente demanda de alimentos, fibras y protección ambiental a nivel mundial, el empobrecimiento de los recursos naturales no renovables y las alteraciones que ha sufrido la calidad ambiental global, requieren con urgencia la construcción de un sistema de modelación que permita evaluar la calidad de los agroecosistemas como parte del conjunto de herramientas para definir y asignar sostenibilidad dentro los mismos (Pérez et al., 2010).

El nitrógeno es el principal elemento nutricional esencial para el desarrollo y productividad de los cultivos, siendo el fósforo el segundo elemento de importancia para el crecimiento de las plantas (Vessey, 2003; Khan et al., 2007). Muchos ecosistemas naturales de países tropicales poseen suelos predominantemente ácidos y deficientes en fósforo (Khan et al., 2007), debido a la fuerte fijación de este elemento como fosfatos insolubles de hierro y aluminio.
La fertilización con nitrógeno y fósforo es una práctica común dirigida a aumentar el rendimiento de los cultivos. Sin embargo, el uso de dosis elevadas de estos fertilizantes, pueden tener efectos negativos en el medio ambiente, y contribuir a la contaminación del suelo, el agua y las áreas naturales. Estos impactos representan una serie de amenazas para la salud humana y animal (Pedraza, 2008). Asimismo, la forma soluble de fósforo presente en los fertilizantes puede ser precipitado después de la aplicación y convertirse en formas insolubles, y no disponibles para las plantas.

Las poblaciones microbianas y sus interacciones son componentes clave en el sistema continuo suelo-planta, afectando al desarrollo de los cultivos. La fijación biológica del nitrógeno atmosférico por bacterias diazotróficas, es el segundo proceso más importante después de la fotosíntesis que se realiza en la naturaleza (Silvia et al., 1998). En la ausencia de fertilizantes nitrogenados o residuos de animales, la dinámica de los agroecosistemas depende completamente de un grupo de microorganismos que tienen la habilidad para reducir el nitrógeno atmosférico a amonio, a través de la síntesis de un complejo enzimático denominado nitrogenasa. Este nitrógeno orgánico es convertido a diferentes formas químicas, las cuales pueden ser utilizadas por las plantas y por los mismos microorganismos para suplir total o parcialmente sus requerimientos de síntesis de proteínas y otros compuestos orgánicos. Este proceso de conversión de nitrógeno atmosférico se debe a que estos microorganismos tienen la capacidad de sintetizar un complejo enzimático denominado nitrogenasa (Geisseler et al., 2010).

Los mecanismos de transformación del fósforo incluyen a las bacterias solubilizadoras de fosfatos que representan una alternativa al uso de fertilizantes químicos al aumentar la disponibilidad de este elemento en el suelo. Pueden solubilizar y mineralizar el fósforo desde fuentes inorgánicas y orgánicas del fósforo total del suelo, actuando como biofertilizantes (Oliveira et al., 2009). La mineralización del fósforo orgánico es llevada a cabo por acción de fosfatasas, mientras que la producción de ácidos es el principal mecanismo por el cual las bacterias solubilizan fosfatos (Antoun, 2012). Estudios realizados por Chuang et al. (2007) sobre la solubilización de fosfatos por parte de hongos en medios de cultivos, demuestran que estos microorganismos solubilizan fósforo insoluble en 
medios de cultivos con una reducción concomitante en el valor del pH, sin importar la fuente de Pi usada. Así mismo estos autores sostienen que el mayor contenido de protones responsable de la reducción del $\mathrm{pH}$ pudo deberse a la producción de ácidos orgánicos y/o a la excreción de $\mathrm{H}^{+}$que acompaña a la asimilación del $\mathrm{NH}_{4}{ }^{+}$presente en el medio.

Las bacterias endófitas son aquellas aisladas de tejidos de plantas desinfectadas superficialmente o de su interior, y que no causan síntomas visibles de enfermedad en la planta (Pérez et al., 2010). Estudios indican que las bacterias endófitas ejercen control biológico sobre fitopatógenos (Sessitch et al., 2002), promueven el crecimiento en las plantas hospederas (Tsavkelova et al., 2007), aumentan la resistencia a enfermedades (Chanway, 1998), contribuyen a la fijación biológica de nitrógeno (Hurek y ReinholdHurek, 2003), solubilización de fosfato (Hameeda et al., 2008) y brindan protección contra patógenos mediante la producción y síntesis de metabolitos secundarios (Berg et al., 2005).

Los microorganismos endófitos han sido reportados como agentes de control para fitopatógenos en diversos cultivos, se ha comprobado que los mecanismos de control biológico mediado por bacterias endófitas están basados en diferentes mecanismos los cuales incluyen antibiosis, la competencia por los nutrientes y nichos $(\mathrm{CNN})$ y la resistencia sistémica inducida (ISR). Hasta ahora, sólo el papel de la ISR en el control biológico mediado por endófitas ha sido confirmado en planta (Pérez et al., 2013).

Asimismo, algunas gramíneas como la caña de azúcar del Brasil, derivan una parte sustancial del nitrógeno de la planta a partir de la fijación biológica de nitrógeno (Muñoz, 2005). La fijación biológica del nitrógeno de las plantas leguminosas es basada en la simbiosis de bacterias fijadoras de nitrógeno con las raíces-nódulos, mientras que otras plantas de importancia agrícola como el maíz, arroz, caña de azúcar, trigo y pasturas pueden beneficiarse de esta asociación con diversas bacterias diazotróficas (James, 2000). Estudios realizado por Hurek y Reinhold-Hurek (2003), identificaron a Azoarcus sp. cepa $\mathrm{BH}_{72}$, como un modelo de bacteria endófita asociada a raíces de arroz con capacidad de fijar biológicamente nitrógeno en tejido de dichas plantas sin causarles daño a ella.

Bacterias endófitas pertenecientes a los géneros Bacillus, Pseudomonas, Serratia, Enterobacter entre otras, han sido reportadas como solubilizadoras de fosfatos insolubles y de promover el crecimiento de las plantas. Hameeda et al. (2008) reportaron que las bacterias Serratia marcescens EB 67 y Pseudomonas sp. incrementan la producción de biomasa en plantas de maíz en condiciones de campo e invernadero, mediante la capacidad de estas de solubilizar fosfatos.

A partir de especies de plantas monocotiledóneas (pastos, trigo, sorgo, maíz y caña de azúcar), se han aislado e identificado numerosas especies de bacterias endófitas diazotróficas (Lara et al., 2011), con capacidad de fijar nitrógeno en cada una de ellas, reduciendo de esta manera la aplicación de fertilizantes químicos (Prakamhang et al., 2009). Asimismo las plantas utilizan menor cantidad de fertilizantes fosfatados que se aplican y el resto se convierte rápidamente en complejos insolubles en el suelo (Vassilev y Vassileva, 2003). Esto conduce a la necesidad de frecuentes aplicaciones de fertilizantes de fosfato, lo cual es costoso y ambientalmente indeseable.

Por todo lo antes expuesto, se plantea la necesidad de aislar bacterias endófitas asociadas a diferentes tejidos del pasto colosoana en el departamento de Sucre y evaluar in vitro su actividad fijadora de nitrógeno y solubilizadora de fósforo, como una alternativa biológica para su uso potencial a mediano plazo como fuente de biofertilizante.

\section{MATERIALES Y MÉTODOS}

\section{Área de estudio}

Durante el primersemestre del 2012, se muestrearon 42 fincas ganaderas sembradas únicamente con pasto colosoana, distribuidas en cuatro zonas agroecológicas pertenecientes al municipio de Corozal, localizado en la región noreste del Departamento de Sucre, a una altura de $174 \mathrm{msnm}$, y está situado a $9^{\circ} 19^{\prime}$ latitud norte y $75^{\circ} 18^{\prime}$ longitud W de Greenwich; extensión de $203,33 \mathrm{~km}^{2}$ y temperatura promedio anual de 27 ${ }^{\circ} \mathrm{C}$. Este municipio de acuerdo a la capacidad, uso y manejo de tierras se encuentra distribuido en cuatro zonas agroecológicas así: zona 1 (III $s c-I V h s)$, zona 2 (VII sc - IV esc), zona 3 (VI sc - VI esc) y zona 4 (VII sc - VII esc) (Pérez et al., 2012), las cuales presentan las siguientes características: 
En la zona 1 (III $s c-I V h s)$, se encontraban suelos pertenecientes a la subclase III sc los cuales presentaban relieve plano a ligeramente inclinado, pendientes entre $1-3 \%$ y $3-4 \%$, suelos moderadamente profundos, imperfectamente drenados, texturas moderadas a finas, permeabilidad moderada a lenta, retención de humedad media a lenta, $\mathrm{pH}$ moderadamente ácida a neutra, alta disponibilidad de calcio (Ca), magnesio $(\mathrm{Mg})$ y potasio $(\mathrm{K})$, bajos contenidos de fósforo (P) disponible, contenidos de materia orgánica bajos a medios y fertilidad baja a moderada. Una de las limitaciones de esta subclase es que tienen profundidad efectiva limitada por horizontes arcillosos compactados, permeabilidad baja, poca capacidad de aireación, contenidos bajos de materia orgánica y fósforo disponible, y falta de humedad. Se encontraban establecidos pastos naturales, maíz, yuca y asocio yuca/ñame.

Los suelos de la subclase $I V h$ s estaba conformado por suelos pobremente drenados, superficiales a muy superficiales, arcillosos, poco permeables, de alta retención de humedad, pegajosos, plásticos, $\mathrm{pH}$ moderado a fuertemente ácido, mediano a altos contenidos de cationes intercambiables, porcentajes de fósforo disponibles y materia orgánica bajos, fertilidad actual moderada. En condiciones actuales son aptos para arroz y pastos naturales resistentes al exceso de humedad.

La zona 2 (VII sc - IV esc), estaba conformada por suelos que pertenecen a la subclase VII sc con suelos fuertemente ondulados, con pendientes de $12-25 \%$, erosión ligera, suelos bien drenados, moderadamente profundos, de texturas moderadas a finas, mediana retención de humedad, permeabilidad moderada. Químicamente son suelos de reacción ácida a neutra y fertilidad moderada. Las principales limitaciones son las pendientes fuertemente onduladas, bajo contenido de nitrógeno, fósforo y materia orgánica. Una parte de esta área está ocupada por ganadería extensiva en pastos naturales y rastrojo. En los suelos de la subclase IV esc están localizados en áreas de relieve ondulado a fuertemente ondulado, con pendientes de $12-25 \%$ y algunos sectores con $1-12 \%$. Son profundos a moderadamente profundos, en su mayoría arcillosos, con inclusiones de texturas moderadamente finas, bien drenados, de media a alta retención de humedad, sufre agrietamiento durante la época seca. Las características químicas indican que tiene reacción ácida a ligeramente alcalina, altos contenidos de calcio, magnesio y potasio, contenidos de materia orgánica y fósforo disponibles bajos. El uso actual es la ganadería extensiva en pastos naturales; en algunos sectores se encontraban cultivos de algodón, maíz, sorgo y yuca.

Entre tanto en la zona 3 (VI sc - VI esc) estaban presentes suelos ubicados en la subclase VI $s c$, en los cuales se encontraban suelos con pendientes de $12-25 \%$ y $25-50 \%$; los suelos son superficiales a moderadamente profundos, de textura franca gruesa a arcillosa, bien a excesivamente drenados. Tienen susceptibilidad a la erosión, buena permeabilidad, mediana a baja retención de humedad, reacción neutra a ligeramente ácida y fertilidad moderada. Las limitaciones para el manejo y uso de estos suelos son la poca disponibilidad de agua, poca profundidad efectiva, contenidos de fósforo disponible, nitrógeno y materia orgánica bajos. El uso actual de estas tierras es la ganadería extensiva con pastos naturales, además se encontraban cultivos como maíz, yuca, ñame y algunos frutales.

En la subclase VI esc se encontraban suelos con pendientes de $12-25 \%$ y $25-50 \%$, presentaban suelos con características morfológicas, físicas y químicas muy variadas, la profundidad efectiva varía de superficial a moderada. Textura franco gruesa a franco fina o arcillosa, fertilidad baja a moderada y reacción ácida a neutra. Las limitaciones de la anterior subclase es de índole química, deficiencia de fósforo y macronutrientes y altos contenidos de aluminio; limitando su aptitud a la preservación de la cobertura vegetal. El mantenimiento de pastos naturales exige severas precauciones (sobre pastoreo) a fin de evitar el progreso de la erosión.

Finalmente, la zona 4 (VII sc - VII esc), está conformada por suelos pertenecientes a la subclase VII sc, en la cual se ubican suelos con pendientes de hasta $12-25 \%$, ligeramente erosionados. Los suelos estaban limitados por capas de gravas muy superficiales, tienen reacción fuertemente ácida, saturación de bases, fósforo y materia orgánica bajos. La altitud para cultivos es baja, debido a la poca profundidad efectiva y a la escasa fertilidad. El mejor uso que se le da actualmente son los pastos. El uso actual es la ganadería extensiva y pequeños cultivos de subsistencia.

En la subclase VII esc se encontraban suelos con pendientes $1-12 ; 12-25 ; 25-50$ y $50-75 \%$, con erosión 
moderada a severa. Los suelos son superficiales a profundos, bien drenados, de baja estabilidad estructural, permeabilidad moderada, retención de humedad de baja a media, reacción ligeramente ácida a neutra y fertilidad moderada a baja. Presentaban limitaciones severas por pendientes fuertemente inclinadas, susceptibles a la erosión y en algunos casos a la baja fertilidad.

\section{Muestreo}

En cada finca ganadera se realizó un muestreo aleatorio. En cada sitio se colectaron diez plantas completas (incluyendo raíces) del pasto. Las muestras fueron identificadas y almacenadas para el transporte al Laboratorio de Investigaciones Microbiológicas de la Universidad de Sucre y procesadas dentro de las 24 horas después de colectadas. De cada planta se separaron raíz, tallo y hojas para el aislamiento de bacterias endófitas.

\section{Aislamiento de bacterias endófitas}

Las plantas colectadas en cada finca ganadera fueron sometidas a un proceso de desinfección superficial. Raíces, tallo y hojas de cada planta fueron lavadas con agua estéril y cortadas en segmento de un $1 \mathrm{~cm}$ aproximadamente. El proceso de desinfección superficial para cada tejido se realizó con base en la metodología propuesta por Pérez et al. (2010).

Después del proceso de desinfección, cada tejido fue colocado en un plato de porcelana y macerado con nitrógeno líquido hasta obtener una mezcla homogénea. De cada homogenizado se prepararon diluciones seriadas, las cuales fueron sembradas por difusión sobre la superficie de agar $\mathrm{R}_{2} \mathrm{~A}$ e incubadas a $28{ }^{\circ} \mathrm{C}$ por 72 horas. La densidad poblacional de bacterias por tejido (UFC/g de tejido), fue estimada por conteo directo de unidades formadoras de colonias en placas. Durante el conteo se observaron y seleccionaron colonias que se distinguían en cuanto a forma, aspecto de la superficie, color y tamaño. Los morfotipos seleccionados fueron purificados y mantenidos en agar $\mathrm{R}_{2} \mathrm{~A}$ para su posterior evaluación in vitro de la actividad solubilizadora de fosfato $\mathrm{y}$ fijadora de nitrógeno.

\section{Evaluación in vitro de actividad de fijación de nitrógeno}

La evaluación cualitativa de la fijación biológica de los aislamientos se realizó por la metodología propuesta por Elbeltagy et al. (2001) en medio selectivo agar ASHBY. Cada uno de los morfotipos aislados fueron sembrados en forma directa sobre la superficie del medio e incubado a $28{ }^{\circ} \mathrm{C}$ por 72 horas. Después de este tiempo, se seleccionaron los morfotipos que fueron capaces de crecer en el medio, indicando la presencia de aquellas bacterias endófitas que poseen el sistema enzimático que les permite reducir el nitrógeno atmosférico y utilizarlo en su metabolismo.

\section{Evaluación in vitro de actividad de solubilización de fosfato}

La evaluación cualitativa de la solubilización de fosfato de los aislamientos se realizó siguiendo la metodología propuesta por Nautiyal (1999) sobre medio NBRIP con $\mathrm{Ca}_{3} \mathrm{PO}_{4}$ como fuente de fósforo insoluble a $\mathrm{pH}$ 7. Cada morfotipo fue inoculado sobre la superficie del medio e incubado a $28{ }^{\circ} \mathrm{C}$ por 72 horas. La capacidad de solubilizar fosfatos se determinó por la formación de halo transparente visible alrededor y debajo de la colonia.

\section{Identificación de aislados seleccionados}

Para la identificación de aislados de bacterias endófitas con actividad positiva para la fijación biológica de nitrógeno y solubilización de fosfato se utilizó el sistema de galerías API20E de la marca Biomeriux. La identificación se realizó mediante el sistema de códigos en software específico que identifica la bacteria mediante un banco de datos (BioMerieux, St Louis, MO, USA).

\section{Análisis estadístico}

El análisis de varianza se realizó por ANOVA multifactorial, para determinar las diferencias entre densidad poblacional (UFC/g de tejido) de bacterias endófitas en función de zona y tipo de tejido. Se utilizó la prueba múltiple de rango (Tukey) para determinar si hubieron diferencias entre las densidades poblacionales de bacterias endófitas (UFC/g de tejidos) con relación 
a zona y tipo de tejido. Los datos fueron analizados mediante el paquete estadístico R. Así mismo para establecer diferencia entre actividad solubilizadora de fosfato y fijadora de nitrógeno de bacterias endófitas por zona, finca y tejido colonizado, se empleó la prueba de Phi V de Cramer para evaluar el efecto en función de ausencia y presencia.

\section{RESULTADOS Y DISCUSIÓN}

\section{Aislamientos obtenidos y densidad poblacional}

Se obtuvieron un total de 84 morfotipos de bacterias endófitas los cuales fueron aislados de diferentes tejidos de pasto colosoana. La densidad poblacional de estas bacterias varió en un rango de $3,24 \times 10^{9} \pm 2,2 \times 10^{10} \mathrm{UFC} / \mathrm{g}$ de tejido. Estudios realizados por Pérez et al. (2010) sobre densidad poblacional de bacterias endófitas asociadas a la especie de pasto colosoana en tres localidades del departamento de Sucre, encontraron densidades promedias de $3,4 \times 10^{3} \pm 5,3 \times 10^{4}$ UFC por g de raíz para esta especie de pasto. Los resultados obtenidos en el presente estudio, encontraron valores superiores de densidad poblacional de bacterias endófitas asociadas a raíz del pasto colosoana en el municipio de Corozal $\left(1,61 \times 10^{10} \mathrm{UFC} / \mathrm{g}\right)$ a lo reportados a la fecha por otros estudios con esta especie de pastura e inclusive los datos obtenidos en este trabajo encontraron valores superiores de presencia de bacterias en tallo 8,75 $\mathrm{x}$ $10^{10} \mathrm{UFC} / \mathrm{g}$ de tejido) y hojas $\left(5,42494 \times 10^{9} \mathrm{UFC} / \mathrm{g}\right.$ de tejido) a los reportados por Pérez et al. (2010).
Los resultados del análisis multifactorial entre densidad poblacional en función a zona, finca y tejidos muestran diferencias altamente significativas para cada variable (Cuadro 1).

Los resultados de la prueba múltiple de rangos para densidad poblacional de bacterias endófitas por zonas (Figura 1), señalan que la zona 4 presentó las mayores densidades poblacionales $\left(2,06 \times 10^{10} \mathrm{UFC} /\right.$ $\mathrm{g}$ de tejido), seguida de la zona $1\left(1,05 \times 10^{10} \mathrm{UFC} / \mathrm{g}\right.$ de tejido) con respecto a las otras dos zonas (2 y 3 ) las cuales presentaron los menores valores, 3,25 x $10^{9} \mathrm{y}$ $4,29 \times 10^{9} \mathrm{UFC} / \mathrm{g}$ de tejido, respectivamente.

La prueba múltiple de rangos para densidad poblacional de bacterias endófitas con respecto a tejido vegetal (Figura 2), muestra diferencias significativas, indicando mayores densidades poblacionales en raíces $\left(1,60907 \times 10^{10} \mathrm{UFC} / \mathrm{g}\right.$ de tejido $)$ y menores para hoja

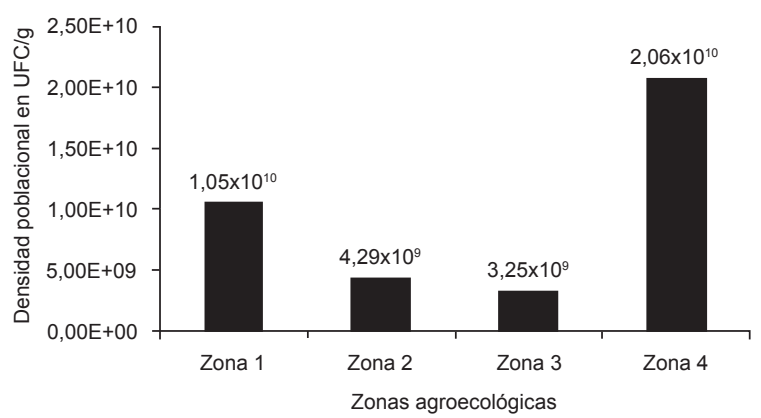

Figura 1. Prueba múltiple de rango para densidad poblacional de bacterias endófitas en función a zonas agroecológicas pertenecientes al municipio de Corozal, Sucre, Colombia. 2012.

Cuadro 1. Análisis multifactorial de densidad poblacional (UFC) de bacterias endófitas en función a zona, finca y tejidos de pasto colosoana pertenecientes a fincas ganaderas departamento de Sucre, Colombia. 2012.

\begin{tabular}{lccccc}
\hline Fuente & Suma de cuadrados & Gl & Cuadrado medio & Razón-F & Valor-P* \\
\hline Efectos principales & & & & & \\
Fincas & $5,56 \times 1021$ & 5 & $1,11 \times 1021$ & 3,34 & 0,0073 \\
Tejido & $2,87 \times 1021$ & 2 & $1,44 \times 1021$ & 4,31 & 0,0154 \\
Zonas & $3,97 \times 1021$ & 3 & $1,32 \times 1021$ & 3,97 & 0,0096 \\
Residuos & $4,13 \times 1022$ & 124 & $3,33 \times 1020$ & & \\
Total (corregido) & $5,35 \times 1022$ & 134 & & & \\
\hline
\end{tabular}

* Diferencia altamente significativa con un $95,0 \%$ de nivel de confianza. 


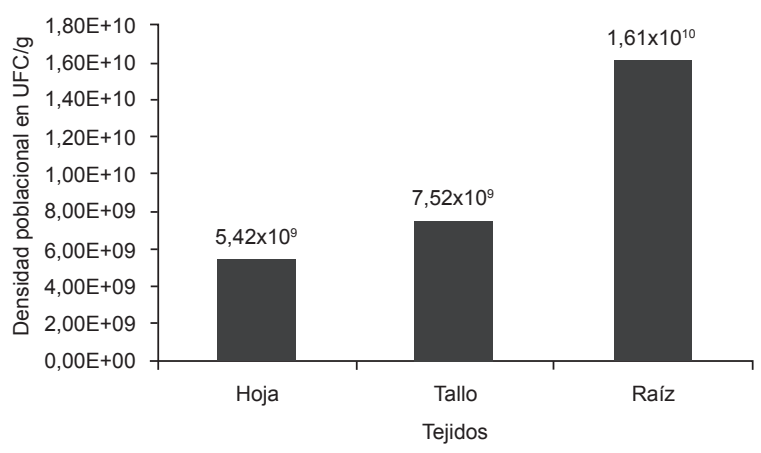

Figura 2. Prueba múltiple de rango para densidad poblacional de bacterias endófitas en función a fincas tejidos de pasto colosoana (Bothriochloa pertusa) ubicado en el municipio de Corozal, Colombia. 2012.

y tallo, respectivamente $\left(5,42 \times 10^{9}\right.$ y $7,52 \times 10^{9} \mathrm{UFC} / \mathrm{g}$ de tejido).

\section{Actividad fijadora de nitrógeno}

De un total de 84 morfotipos aislados de bacterias endófitas, 53 presentaron actividad positiva para fijación biológica de nitrógeno in vitro (Figura 3). Los resultados de la prueba de Phi V de Cramer con respecto ausencia o presencia de actividad fijadora de nitrógeno en función de tejidos mostró diferencia significativa. La mayor presencia de morfotipos fue observada en la raíz (29/23), con presencia de 23 aislados que mostraron actividad positiva para fijación biológica de nitrógeno in vitro, con respecto a hoja (32/21) y tallo (15/9) (Figura 4).

\section{Actividad solubilización de fosfato}

De los 84 morfotipos de bacterias endófitas aisladas, 59 de estos presentaron actividad positiva para la solubilización de fosfatos in vitro (Figura 5). Los resultados de Phi V de Cramer mostraron diferencias del efecto de zona con respecto a la presencia o ausencia de bacterias solubilizadoras de fosfatos. En la Figura 5 se observa que la mayor presencia de morfotipos aislado se reportó para la zona $2(35 / 29)$, con presencia 29 aislados que mostraron actividad positiva para solubilización de fosfatos in vitro, con respecto al resto de zonas.

La mayoría de los aislados evaluados in vitro con actividad positiva para solubilización de fosfatos

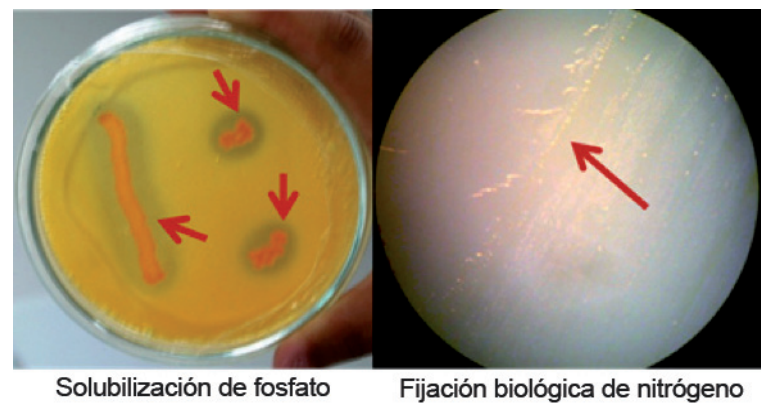

Figura 3. Actividad solubilizadora de fosfato y fijación biológica de nitrógeno in vitro de bacterias endófitas asiladas de pasto colosoana (Bothriochloa pertusa) pertenecientes a fincas ganaderas departamento de Sucre, Colombia 2012. Fuente: Pérez (2012).

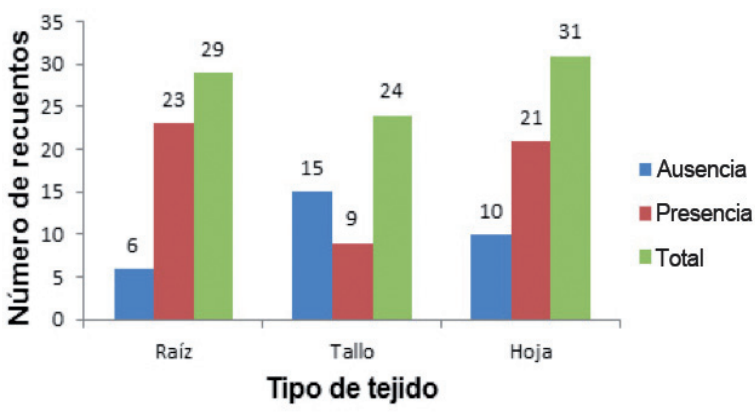

Figura 4. Presencia y ausencia de actividad fijadora de nitrógeno de bacterias endófitas con respecto a tejidos de pasto colosoana mediante prueba de Phi V de Cramer, en cuatro zonas agroecológicas del municipio de Corozal, Colombia. 2012.

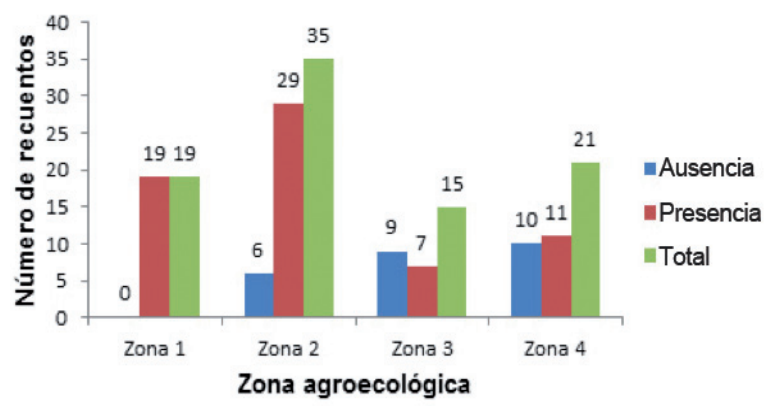

Figura 5. Presencia y ausencia de actividad solubilizadora de fosfato de bacterias endófitas asilada de pasto colosoana (Bothriochloa pertusa), mediante Prueba de Phi V de Cramer, en cuatro zonas agroecológicas del municipio de Corozal, Colombia. 2012. 
correspondieron al grupo de bacterias Gram-negativa $(n=34 / 59)$, mientras que los números menores se ubicaron dentro del de bacterias Gram-positivas (25/59). Asimismo la presencia de estas que mostraron mayor actividad positiva para fijación biológica del nitrógeno, se ubicaron dentro del grupo de bacterias Gram-negativas $(n=42 / 53)$ respecto al menor número, las cuales correspondieron a bacterias Gram-positivas (11/53).

\section{Identificación}

De acuerdo al sistema API20E se identificaron tres especies y/o grupos de bacterias aisladas siguiendo la metodología descrita, y presentaron actividad positiva para fijación biológica de nitrógeno y solubilización de fosfatos. Se confirmó la identidad de las bacterias endófitas: Aeromonas salmonicida, Alcaligenes sp. y Pasteurella pneumotrofica como fijadoras de nitrógeno. Asimismo fue confirmada: Alcaligenes sp., Aeromonas salmonicida y Pasteurella pneumotrofica como solubilizadoras de fosfatos en tejidos del pasto colosoana (Cuadro 2).

Los resultados obtenidos identificaron como bacteria endófita a A. salmonicida, la cual, de acuerdo a literatura, corresponde a una bacteria Gram-negativa de forma bacilar inmóvil. Esta tiene amplia distribución en aguas dulces y saladas, también se encuentran en aguas negras y suelo. Es considerada saprófita del intestino de los animales, afecta principalmente a los de sangre fría (reptiles, peces y anfibios), al hombre y raramente a los de sangre caliente (Dallaire-Dufresne et al., 2013). Por otra parte, P. pneumotropica ha sido reportada como una bacteria Gram-negativa oportunista, cocobacilos inmóviles presentes en la flora orofaríngea y respiratoria de numerosos animales, incluyendo perros, gatos y roedores (Fernández et al., 2011).

Según el análisis realizado, se logró identificar además a $A$. salmonicida identificada como bacteria endófita asociada a tallo y hoja de pasto colosoana y encontrada en las zonas 3 y 4 , respectivamente. La prueba in vitro de fijación biológica de nitrógeno, mostró que esta bacteria además de fijarlo biológicamente tuvo la capacidad de solubilizar fosfato y se encontró que esta actividad fue observada en morfotipos aislados de raíces pertenecientes a la zona 3. En estudios realizados por Chye et al. (2013) sobre diversidad de bacterias asociadas a plantas monocotiledóneas y dicotiledóneas de Malasia, identificaron especies dentro del género Aeromonas y Pasteurella pneumotropica como bacterias endófitas en esas especies vegetales.

Otro estudio realizado sobre presencia de bacterias asociadas al suelo y a la rizosfera de donde crece la especie vegetal conocida vulgarmente como lengua de vaca, identificaron a la bacteria Alcaligenes faecalis, quien además fue evaluada in vitro y demostró capacidad de fijar nitrógeno (Hansen et

Cuadro 2. Bacterias endófitas con actividad fijadoras de nitrógeno y solubilizadoras de fosfatos aisladas de pasto colosoana identificadas mediante sistema API20E. Sucre, Colombia. 2012.

\begin{tabular}{|c|c|c|c|}
\hline Morfotipos aislados & Especie y/o grupo de bacteria & $\begin{array}{l}\text { Actividad de fijación } \\
\text { biológica de nitrógeno }\end{array}$ & $\begin{array}{l}\text { Actividad in vitro de } \\
\text { solubilización de fosfato }\end{array}$ \\
\hline M5HZ4 & Aeromonas salmonicida & $(+)$ & $(-)$ \\
\hline M57TZ3 & Aeromonas salmonicida & $(+)$ & $(-)$ \\
\hline M18RZ4 & Alcaligenes sp. & $(+)$ & $(+)$ \\
\hline M3TZ4 & Aeromonas salmonicida & $(+)$ & $(+)$ \\
\hline M52HZ4 & Aeromonas salmonicida & $(-)$ & $(+)$ \\
\hline M2HZ1 & Pasteurella pneumotropica & $(-)$ & $(+)$ \\
\hline M14RZ1 & Aeromonas salmonicida & $(+)$ & $(+)$ \\
\hline M58TZ3 & Pasteurella pneumotropica & $(+)$ & $(-)$ \\
\hline
\end{tabular}

M: morfotipo, R: raíz, T: tallo, H: hoja y Z: zona agroecológica. (+): actividad positiva, (-): actividad negativa. 
al., 2003; Lin et al., 2007). Por otra parte, un estudio llevado a cabo en el suroeste de Etiopía en bosque donde crece Coffea arabica, se identificó y evaluó a Aeromonas, Alcaligenes y Pasteurella, como bacterias solubilizadoras de fosfato asociadas a la rizosfera de esta planta de café (Muleta et al., 2012).

Los resultados estadísticos de presencia y ausencia de bacterias endófitas con capacidad de fijar biológicamente nitrógeno in vitro, muestran que la mayor presencia de estas bacterias con dicha actividad se encontró en mayor número, en las raíces con respecto a hojas y tallos. Sin embargo A. salmonicida mostró esta actividad in vitro cuando se encontraron asociadas a tallos y hojas, y solamente se observó en $P$. neumotropica esta actividad de muestras colectadas en raíces. Reinhold-Hurek y Hurek (1998) en su estudio sobre la capacidad de bacterias diazotróficas de fijar nitrógeno en especie de pastos, identificaron a Azoarcus sp. asociada a raíz, base del tallo y tallo de la especie de pasto Killar en raicillas y hoja y Herbaspirillum seropedicae y $H$. rubrisubalbicans, en sorgo, fijando biológicamente nitrógeno en esos tejidos.

La primera bacteria ácido acético (AAB) fijadora de nitrógeno fue descrita en Brasil, asociada a tejidos de la planta de caña de azúcar, la cual inicialmente fue denominada Acetobacter diazotrophicus, y posteriormente reclasificada como Gluconacetobacter diazotrophicus. Más tarde, dos nuevas especies dentro del género Gluconacetobacter, asociados a las plantas de café, fueron reportadas en México como: G. johannae y G. azotocaptans. La bacteria Swaminathania salitolerans ha sido reportada como una bacteria endófitas asociada a plantas de arroz tolerante a la salinidad y se ha descrito la presencia de Acetobacter peroxydans asociada a cultivos de arroz en la India con capacidad de fijar biológicamente nitrógeno.

Los aislamientos de Pasteurella pneumotrofica se obtuvieron a partir de hojas de muestras colectadas en la zona 1, la cual demostró in vitro la capacidad de solubilizar fosfato. Asimismo se observó que esta bacteria aislada de tallo colectada de la zona 3, demostró además la capacidad de fijar biológicamente nitrógeno in vitro. Kuklinsky-Sobral et al. (2004) demostraron que bacterias endófitas pertenecientes a las familias Pseudomonaceae, Burkholderiacea y Enterobacterias asociadas a plantas de soya, mostró que estas bacterias tienen la capacidad de producir ácido índol acético (IAA) y de solubilizar de fosfato in vitro. El $34 \%$ de las bacterias produjeron IAA y el $49 \%$ fueron capaces de solubilizar fosfato. Además fue demostrado que el $60 \%$ de estas bacterias endófitas producen ácido indol acético, solubilizan el fosfato mineral e in vitro fijan biológicamente el nitrógeno.

A la fecha del presente estudio no se encontraron reporte en bases de datos internacionales de A. salmonicida y P. neumotropica como bacterias endófitas asociadas a pasto colosoana con capacidad de solubilizar fosfatos y fijar biológicamente nitrógeno. Sin embargo, para el caso de la caña de azúcar en Brasil se ha demostrado la importancia que tiene la bacteria endófita Azoarcus sp., dado que suple en un $70 \%$ las necesidades de nitrógeno a través de la fijación biológica de nitrógeno. Esto podría indicar que las dos especies de bacterias endófitas identificadas en el presente trabajo, podrían ser utilizadas como una alternativa biológica de fertilización a base de fósforo y nitrógeno para el cultivo. Como perspectivas futuras se plantea en primer lugar la identificación a nivel molecular de las bacterias promisorias, utilizando cebadores específicos para verificar su identidad y compararla con la homología existente en registros de bancos mundiales. Además, es de interés conocer el efecto de la inoculación de estas bacterias sobre el cultivo de pasto colosoana en ensayos a campo, con el fin de evaluar in vivo la eficiencia de estas endófitas como una alternativa biológica que supla o complemente las demandas de fósforo y nitrógeno.

\section{LITERATURA CITADA}

Aguilera, M.M. 2005. Documento de trabajo sobre economía regional. Economía Regional: La Economía del Departamento de Sucre: Ganadería y Sector Público. Ediciones Banco Ganadero, Sincelejo, Colombia.

Antoun, H. 2012. Beneficial microorganisms for the sustainable use of phosphates in agriculture. Procedia Eng. 46:62-67.

Berg, G., A. Krechel, M. Ditz, A. Sikora, A. Ulrich, y J. Hallmann. 2005. Endophytic and ectophytic potato-associated bacterial communities differ in structure and antagonistic function against plant pathogenic fungi. FEMS Microbiol. Ecol. 5:215-229.

Chanway, C.P. 1998. Bacterial endophytic: ecological and practical implications. Sydowia 50:149-170.

Chuang, C., Y.L. Kuo, C. Chao, y W. Chao. 2007. Solubilization of inorganic phosphates and plant growth promotion by Aspergillus niger. Biol. Fert. Soils 43:575-584. 
Chye, Y., Y. Yin, R. Rohani, J.F. Weber, y S. Bhore. 2013. Diversity of endophytic bacteria in Malaysian plants as revealed by $16 \mathrm{~S}$ rRNA encoding gene sequence based method of bacterial identification. J. Young Pharm. 5:95-97.

Dallaire-Dufresne, S., K. Tanaka, M. Trudel, A. Lafaille, y S. Charette. 2013. Virulence genomic features, and plasticity of Aeromonas salmonicida subsp. salmonicida the causative agent of fish furunculosis. Vet. Microbiol. 28:1-7.

Elbeltagy, A., K. Nishioka, T. Sato, H. Suzuki, B. Ye, T. Hamada, T. Isawa, H. Mitsui, y K. Minamisawa. 2001. Endophytic colonization and in plant a nitrogen fixation by a Herbaspirillum sp. isolated from wild rice species. Appl. Environ. Microbiol. 67:5285-5293.

Fernández, F., L.R. Puerta, C.I. Rodríguez, y A.J. Fuente. 2011. Absceso epidural por Pasteurella pneumotropica. Enferm. Infecc. Microbiol. Clín. 29(8):631-638.

Geisseler, D., W. Horwath, R. Joergensen, B. Ludwig. 2010. Pathways of nitrogen utilization by soil microorganisms: A review. Soil Biol. Biochem. 42:2058-2067.

Hansen, M., R. De Fries, J. Townshend, M.C. Dimiceli, y R. Sohlberg. 2003. Global percent tree cover at a spatial resolution of 500 meters: first results of the MODIS Vegetation Continuous Fields algorithm. Earth Interactions 7(10):1-15.

Hameeda, B., G. Harini, O.P. Rupela, S.P. Wani, y R. Gopal. 2008. Growth promotion of maize by phosphate solubilizing bacteria isolated from composts and macrofauna. Microbiol. Res. 163:234-242.

Hurek, T., y B. Reinhold-Hurek. 2003. Azoarcus sp. strain BH72 as a model for nitrogen-fixing grass endophytes. J. Biotechnol. 106:169-178.

James, E.K. 2000. Nitrogen fixation in endophytic and associative symbiosis. Field Crops Res. 65:197-209.

Khan, M.S., A. Zaidi, y P. Wani. 2007. Role of phosphatesolubilizing microorganisms in sustainable agriculture - a review. Agron. Sustain. Dev. 27:29-43.

Kuklinsky, S.J., W. Araújo, R. Mendes, I. Olívio, K.A. Pizzirani, y J. Azevedo. 2004. Isolation and characterization of soybean-associated bacteria and their potential for plant growth promotion. Environ. Microbiol. 6:1244-1251.

Lara, C., L. Oviedo, y A. Alemán. 2011. Aislados nativos con potencial en la producción de ácido indol acético para mejorar la agricultura. Biotecnología en el Sector Agropecuario y Agroindustrial 9(1):17-23.

Lin, J.H., E.T. Wang, W.F. Chen, y W.X. Chen. 2007. Genetic diversity and potential for promotion of plant growth detected in nodule endophytic bacteria of soybean grown in Heilongjiang province of China. Soil Biol. Biochem. 40:238-246.

Muleta, D., F. Aseffa, E. Borjesson, y U. Granhall. 2012. Fosfato-solubulizantes rizobacterias asociadas con Coffea arabica L. en los bosques naturales del café del suroeste de Etiopia. Diario de la Sociedada Saudita de Ciencias Agrícolas 12(1):73-84.

Muñoz, R.J. 2005. La interacción Gluconacetobacter diazotrophicus-caña. La caña de azúcar y las bacterias endófitas. Revista Elemento: Ciencia y Cultura 12(57):57-62.

Nautiyal, C. 1999. An efficient microbiological growth medium for screening phosphate solubilizing microorganism. FEMS Microbiol. Lett. 170:264-270.

Oliveira, C.A., V. Alves, I. Marriel, E. Gomes, M. Scotti, N.P. Carneiro, C.T. Guimaraes, R.E. Schaffert, y N. Sá. 2009. Phosphate solubilizing microorganisms isolated from rhizosphere of maize cultivated in an oxisol of the Brazilian Cerrado Biome. Soil Biol. Biochem. 41:1782-1787.

Prakamhang, J., K. Minamisawa, K. Teamtaisong, N. Boonkerd, y N. Teaumroong. 2009. The communities of endophytic diazotrophic bacteria in cultivated rice (Oryza sativa L.). Appl. Soil Ecol. 42:141-149.

Pedraza, R. 2008. Recent advances in nitrogen-fixing acetic acid bacteria. International J. Food Microbiol. 125:2535.

Pérez, A., C. Botero, y M. Cepero. 2012. Diversidad de micorrizas arbusculares en pasto colosuana (Bothriochloa pertusa (L) A. Camus de fincas ganaderas del municipio de Corozal-Sucre. Rev. MVZ Córdoba 17:3024-3032.

Pérez, C.A., A.L. Chamorro, y C.C. Pérez. 2013. Bacterias endófitas: un nuevo campo de investigación para el desarrollo del sector agropecuario. Rev. Colombiana Cien. Anim. 5:439-462.

Pérez, C.R., C.A. Pérez, M.M. Vertel. 2010. Caracterización nutricional, fisicoquímica y microbiológica de tres abonos orgánicos para uso en agroecosistemas de pasturas en la subregión sabanas del departamento de Sucre, Colombia. Revista Tumbaga 5:27-37. 
Perez, C.A., S.J. Rojas, y C.J. Fuente. 2010. Diversidad de bacterias endófitas asociadas a raíces del pasto colosuana (Bothriochloa pertusa) en tres localidades del departamento de Sucre, Colombia. Revista Acta Biológica Colombiana 15:1-18.

Reinhold,H.B., y T.Hurek. 1998. Life in grasses: diazotrophic endophytic. Trends Microbiol. 6:139-143.

Sessitsch, A., B. Reiter, U. Pfeifer, y E. Wilhelm. 2002. Cultivation-independent population analysis of bacterial endophytic in three potato varieties based on eubacterial and Actinomycetes-specific PCR of $16 \mathrm{~S}$ rRNA genes. FEMS Microbiol. Ecol. 39:23-32.
Silvia, D., H.P. Fuhrmann, y D. Zuberer. 1998. Principles and applications of soil microbiology. Prentice Hall. New Jersey, USA.

Tsavkelova, E., T. Cherdyntseva, S. Botina, y A. Netrusov. 2007. Bacteria associated with orchid roots and microbial production of auxin. Microbiol. Res. 162:69-76.

Vessey, J.K. 2003. Plant growth promoting rhizobacteria as biofertilizers. Plant and Soil 255:571-586.

Vassilev, N., y M. Vassileva. 2003. Biotechnological solubilization of rock phosphate on media containing agro-industrial wastes. Appl. Microbiol. Biot. 61:435-440. 
